\title{
Treatment Transitions in Chronic Obstructive Pulmonary Disease: Retrospective Analyses of US and UK Healthcare Databases
}

\author{
Chloe I. Bloom (D) · Jukka Montonen · Olaf Jöns · Elizabeth M. Garry • \\ Surya P. Bhatt
}

Received: September 22, 2021 / Accepted: November 22, 2021 / Published online: January 10, 2022

(c) The Author(s) 2022

\begin{abstract}
Introduction: Previous studies have reported that more patients receive inhaled corticosteroid (ICS)-containing therapies than would be expected based on exacerbation history, suggesting overprescribing. We aimed to describe patterns of treatment switching from first (1MT) to second maintenance therapy (2MT) among COPD patients in the US and UK.

Methods: We used healthcare data from the US IBM $^{\circledR}$ MarketScan ${ }^{\circledR}$ and UK Clinical Practice Research Datalink databases (2015 - 2018) to assess transitions between 1MT and 2MT among COPD patients. Patients with a recorded asthma diagnosis prior to $1 \mathrm{MT}$ were excluded. We
\end{abstract}

Supplementary Information The online version contains supplementary material available at https:// doi.org/10.1007/s41030-021-00180-7.

\section{I. Bloom (ه)}

Imperial College London, London, UK

e-mail: chloe.bloom06@imperial.ac.uk

J. Montonen · O. Jöns

Boehringer Ingelheim International $\mathrm{GmbH}$,

Ingelheim am Rhein, Germany

E. M. Garry

Aetion Inc., Boston, MA, USA

\section{S. P. Bhatt}

Division of Pulmonary, Allergy and Critical Care Medicine, University of Alabama at Birmingham, Birmingham, AL, USA assessed whether prescribed treatments (longacting muscarinic antagonists [LAMA], longacting $\beta_{2}$-agonists [LABA], inhaled corticosteroids [ICS], as monotherapy or in combination) were consistent with global and national recommendations for COPD, identified patient characteristics associated with treatment transitions, and evaluated treatment duration.

Results: Overall, 7028 patients in the US and 2461 in the UK initiated 2MT within a median (IQR) 160.0 (76.0; 335.0) and $218.0(86.0 ; 428.0)$ days after $1 \mathrm{MT}$, respectively. In the US, $33.6 \%$ of patients initiating 2MT had no recorded exacerbations in the previous year, whereas $23.1 \%$ had one and $43.3 \%$ had $\geq 2$. In the UK, $54.9 \%$ of patients had no recorded exacerbations in the previous year, whereas $20.9 \%$ had one and $24.2 \%$ had $\geq 2$. At $2 \mathrm{MT}$, most patients switched to LAMA/LABA/ICS (26.1\%) or LABA/ICS (25.8\%) in the US, and LAMA/LABA (39.4\%) or LAMA/LABA/ICS (27.8\%) in the UK; $62.2 \%$ (US) and $47.5 \%$ of patients (UK) were prescribed ICScontaining regimens. The most common treatment transition from 1MT to 2MT was LABA/ ICS to LAMA/LABA/ICS (13.0\%) in the US; and LAMA to LAMA/LABA (32.5\%) and LAMA to LAMA/LABA/ICS (14.3\%) in the UK.

Conclusions: At 2MT, the proportion of patients on LAMA/LABA/ICS was similar between the US and UK, but treatment pathways were different. 


\section{PLAIN LANGUAGE SUMMARY}

People with chronic obstructive pulmonary disease (COPD) take inhaled medication to control symptoms such as breathlessness and cough. There are two types of inhaler: 'reliever' inhalers for immediate symptom relief, and 'maintenance' inhalers for long-term disease control. Maintenance inhalers can be used on their own or together, and treatment is often escalated based on the persistence of symptoms or exacerbations (flare-ups), for which inhaled corticosteroids (ICS) are often prescribed. We wanted to see whether doctors' prescribing habits are in line with clinical guidelines, so we looked at data from COPD patients who switched from their first maintenance therapy (1MT) to a second, different maintenance therapy (2MT) between 2015 and 2018. Our data sources were a US health claims database ( $\sim 7000$ patients) and a UK general practice database ( $\sim 2500$ patients). We excluded people with a diagnosis of both COPD and asthma, as similar inhalers are used to treat these two conditions, although the clinical decisions for when to prescribe them differ. On average, the time between 1MT and 2MT was 160 days (US) and 218 days (UK). Overall, 50\% (UK) and 60\% of patients (US) were prescribed ICS as part of their treatment regimen at 2MT, and ICS use in both countries was higher than expected based on the guidelines, which recommend ICS only for patients with severe COPD who meet certain criteria. This means that some patients are being given medication without a known clinical benefit, which puts them at risk of side effects, possibly increasing unnecessary healthcare costs.

Keywords: Bronchodilators; Clinical guidelines; COPD; Database; Inhaled corticosteroid; Long-acting beta-agonists; Long-acting muscarinic antagonists; Maintenance therapy; Observational study; Treatment switching

\section{Key Summary Points}

We analyzed $\sim 7000$ patients in the US and $\sim 2500$ patients in the UK who switched from their first maintenance therapy (1MT) for COPD to a second maintenance therapy (2MT), after an average of 160 days and 218 days, respectively.

In the US, 60\% of patients were prescribed treatment regimens containing inhaled corticosteroids (ICS) at 2MT; most patients switched from their 1MT to either a long-acting $\beta_{2}$-agonist plus ICS (LABA/ ICS; $26 \%$ ) or a combination of a longacting muscarinic antagonist (LAMA) and LABA, together with ICS (LAMA/LABA/ ICS; 26\%) at 2MT.

In the UK, $\sim 50 \%$ of patients were prescribed treatment regimens containing ICS at 2MT; most patients switched from their $1 \mathrm{MT}$ to either LAMA/LABA (39\%) or LAMA/LABA/ICS (28\%) at 2MT.

In the US, the most common transition from 1MT to 2MT was LABA/ICS to LAMA/LABA/ICS (13\%). In the UK, the most common transition was LAMA to LAMA/LABA (32\%), followed by LAMA to LAMA/LABA/ICS (14\%).

At 2MT, the proportion of patients on LAMA/LABA/ICS was similar between the US and UK ( $26 \%$ vs. $28 \%$ ), but the treatment pathways were different.

\section{INTRODUCTION}

Chronic obstructive pulmonary disease (COPD) imposes a heavy burden globally [1], including significant morbidity and mortality and substantial healthcare costs [2-6]. According to the Global Initiative for Chronic Obstructive Lung Disease (GOLD) 2021 strategy report, the primary goals of COPD treatment are to reduce 
symptoms, decrease the risk of exacerbations, and improve health status and exercise tolerance [7].

The GOLD recommendations provide guidance for initiating pharmacologic management of COPD using the ABCD assessment scheme [7], which is discussed in some detail in the accompanying paper in this issue. In this analysis, rather than initiation of therapy, we focus on follow-up management of COPD. According to GOLD, when changing therapy, factors affecting treatment choice include symptoms, exacerbation risk and occurrence of pneumonia, as described in Table 1 [7]. Guidelines from the American Thoracic Society (ATS) also use breathlessness and exacerbation history as guiding factors. LAMA/LABA is recommended over LAMA or LABA monotherapy in patients with COPD and dyspnea or exercise intolerance [8]. Triple therapy (LAMA/LABA/ ICS) is only recommended for those with $\geq 1$ exacerbation in the past year despite being on dual bronchodilator therapy, whereas ICS withdrawal is recommended for patients receiving triple therapy who have had no exacerbations in the past year [8]. In addition, the European Respiratory Society recommends that in patients receiving ICS without a history of exacerbations or a low eosinophil count, withdrawal of ICS is recommended in order to avoid any potential associated side effects, including pneumonia [9]. In the UK, the National Institute for Health and Care Excellence (NICE) recommends that patients are treated with a LAMA/LABA unless they have features suggesting asthma or steroid responsiveness, in which case they should be offered LABA/ICS [10]. According to NICE, patients on LABA/ICS should be considered for treatment with triple therapy if they experience frequent exacerbations in the previous year $(\geq 2$ moderate exacerbations or $\geq 1$ exacerbation leading to hospitalization) or if their day-to-day symptoms adversely impact their quality of life [10].

Despite clear guidance that ICS should be reserved for patients with asthma, a history of exacerbations or high levels of blood eosinophils, evidence from real-world studies suggests that ICS are often inappropriately prescribed [11-14], which can expose patients to the unnecessary risk of side effects such as pneumonia, osteoporosis and diabetes [15-18]. In the accompanying paper in this issue, we report that more patients in both the US and UK received ICS-containing therapies at initiation of first maintenance therapy (1MT) than would be expected based on their exacerbation history, suggesting overprescribing. In this analysis, we aimed to investigate if prescribing habits at second maintenance therapy (2MT) also differed from global and national recommendations for maintenance therapy and between countries.

To do this, we conducted a study using two databases from the US and UK. Our objectives were to evaluate the treatment transitions between 1MT and 2MT among patients with COPD (without prior asthma), and their patterns of treatment switching, including time to treatment switch. We also assessed their demographic and clinical characteristics, including exacerbations, comorbidities and concomitant medication use at the initiation of $1 \mathrm{MT}$ and 2MT.

\section{METHODS}

\section{Study Design and Patients}

These retrospective cohort studies analyzed longitudinal healthcare records from the US and the UK. US data were drawn from the IBM $^{\circledR}$ MarketScan ${ }^{\circledR}$ claims databases, whereas UK data were drawn from Clinical Practice Research Datalink (CPRD) GOLD electronic health records. Further details on these databases are provided in the accompanying paper in this issue. As this was an observational study based on de-identified patient-level data from healthcare databases reported in aggregate only, the study did not require ethics committee approval, nor were subjects required to provide informed consent.

Patients eligible for inclusion were $\geq 40$ years old on the cohort entry date, with a recorded COPD diagnosis (first patient health claim for COPD [US]; first appearance of Read code in CPRD database [UK]; Supplementary Table 2) but no asthma diagnosis, 
Table 1 Recommendations for use of long-acting bronchodilators and/or ICS in patients with COPD

\begin{tabular}{|c|c|c|}
\hline & Long-acting bronchodilators & ICS \\
\hline $\begin{array}{l}\text { GOLD } \\
2021 \\
{[7]}\end{array}$ & $\begin{array}{l}\text { Escalate LAMA or LABA monotherapy to LAMA/ } \\
\text { LABA for patients with dyspnea as the predominant } \\
\text { trait } \\
\text { Escalate LAMA or LABA monotherapy to LAMA/ } \\
\text { LABA for patients with exacerbations as the } \\
\text { predominant trait, unless: } \\
\text {-Eosinophil levels are } \geq 300 \text { cells } / \mu \text { OR } \\
\text {-Eosinophils are } \geq 100 \text { cells } / \mu \text { and } \geq 2 \text { moderate } \\
\text { exacerbations (or } \geq 1 \text { exacerbation leading to } \\
\text { hospitalization) are experienced in the previous year }\end{array}$ & $\begin{array}{l}\text { LABA/ICS should be considered if: } \\
\text {-Eosinophil levels are } \geq 300 \text { cells/ } \mu \text { l OR } \\
\text {-Eosinophils are } \geq 100 \text { cells/ } \mu \text { l and } \geq 2 \text { moderate } \\
\text { exacerbations (or } \geq 1 \text { exacerbation leading to } \\
\text { hospitalization) are experienced in the previous year } \\
\text { For patients on LABA/ICS or LAMA/LABA/ICS, de- } \\
\text { escalation of ICS or a switch to LAMA/LABA should } \\
\text { be considered if there is a lack of response to ICS or if } \\
\text { pneumonia develops }\end{array}$ \\
\hline $\begin{array}{r}\text { ATS } \\
{[8]}\end{array}$ & $\begin{array}{l}\text { Use LAMA/LABA over LAMA or LABA } \\
\text { monotherapy in patients with COPD and dyspnea or } \\
\text { exercise intolerance [strong recommendation] }\end{array}$ & $\begin{array}{l}\text { Use triple therapy (LAMA/LABA/ICS) in patients } \\
\text { with COPD and dyspnea or exercise intolerance } \\
\text { (despite LAMA/LABA dual therapy) who have } \\
\text { experienced } \geq 1 \text { exacerbations in the past year } \\
\text { [conditional recommendation] } \\
\text { Consider ICS withdrawal for patients receiving triple } \\
\text { therapy (LAMA/LABA/ICS) if no exacerbations in } \\
\text { the past year [conditional recommendation] }\end{array}$ \\
\hline $\begin{array}{r}\text { NICE } \\
{[10]}\end{array}$ & $\begin{array}{l}\text { Offer LAMA/LABA to patients with COPD who: } \\
\text {-Do not have asthmatic features/features suggesting } \\
\text { steroid responsiveness AND } \\
\text {-Remain breathless or have exacerbations }{ }^{a}\end{array}$ & $\begin{array}{l}\text { Consider LABA/ICS for patients with COPD who: } \\
\text {-Have asthmatic features/features suggesting steroid } \\
\text { responsiveness AND } \\
\text {-Remain breathless or have exacerbations }{ }^{\mathrm{a}} \\
\text { For patients with COPD who are taking LABA/ICS, } \\
\text { offer LAMA/LABA/ICS if: } \\
\text {-Their day-to-day symptoms continue to adversely } \\
\text { impact their quality of life OR } \\
\text {-They have a severe exacerbation (requiring } \\
\text { hospitalization) OR } \\
\text {-They have two moderate exacerbations within a year } \\
\text { For patients with COPD who are taking } \\
\text { LAMA + LABA, consider LAMA + LABA + ICS } \\
\text { if: } \\
\text {-They have a severe exacerbation (requiring } \\
\text { hospitalization) OR } \\
\text {-They have two moderate exacerbations within a year }\end{array}$ \\
\hline
\end{tabular}


Table 1 continued

\begin{tabular}{lll}
\hline \multicolumn{1}{c}{ Long-acting bronchodilators } & ICS \\
\hline ERS [9] N/A & Withdraw ICS in patients with COPD without a \\
& history of frequent exacerbations [conditional \\
& recommendation] \\
& Do not withdraw ICS in patients with blood \\
& eosinophil counts $\geq 300$ eosinophils/ $\mu$ l strong \\
& recommendation] \\
& Treat with one or two long-acting bronchodilators if \\
& ICS are withdrawn [strong recommendation]
\end{tabular}

ICS inhaled corticosteroids, $L A B A$ long-acting $\beta_{2}$-agonist, $L A M A$ long-acting muscarinic antagonist, $N / A$ not applicable ${ }^{a}$ Despite having used or been offered treatment for tobacco dependence if they smoke AND optimized non-pharmacologic management and relevant vaccinations AND using a short-acting bronchodilator

and $\geq 12$ months of continuous enrollment in the US and UK databases prior to COPD diagnosis. More details regarding definitions for diagnosis of COPD in the US and UK are provided in the accompanying paper in this issue.

Eligible patients initiated maintenance therapy in the form of LAMA, LABA or ICS (monotherapy, dual or triple therapy) between 21 May 2015 and 31 March 2018 for 1MT and between 22 June 2015 and 31 March 2018 for $2 \mathrm{MT}$ in the US (based on dispensing records), and between 1 July 2015 and 31 Dec 2018 for 1MT and between 2 August 2015 and 31 Dec 2018 for 2MT in the UK (based on prescriptions).

Maintenance therapy was defined as at least 30 days of continuous use of monotherapy, dual therapy or triple therapy, including a 14-day allowable gap between individual drug fills to account for possible under-dosing of maintenance therapies and skipping or forgetting to take doses. 1MT was defined as the first occurrence of any of the study therapies after recorded diagnosis of COPD, and 2MT was defined as any subsequent therapy that differed from 1MT, at least 30 days after the initiation of 1MT. Patients receiving 1MT were followed up until end of study period, end of continuous enrollment, or death. Patients diagnosed with asthma during the follow-up period were censored at the time of asthma diagnosis, and therefore not included in the analysis.

\section{Study Variables}

Demographic and clinical characteristics of eligible patients (see Supplementary Table 2 for diagnosis codes) were assessed at the following times: (1) date of initiation of any monotherapy, dual therapy or triple combination of LAMA, LABA or ICS as 1MT after 21 May 2015 (US) or 1 July 2015 (UK); (2) date of initiation of any monotherapy, dual therapy or triple combination of LAMA, LABA or ICS as 2MT after $1 \mathrm{MT}$.

In the same cohort, we identified the treatment transitions between 1MT and 2MT. In addition, we calculated the percentage of patients who used each type of therapy class at 1MT and 2MT, and evaluated the time between 1MT and 2MT. Data were analyzed both overall and stratified by maintenance therapy regimen.

The number of COPD exacerbations was estimated during the year prior to the date of 2MT. In the US, COPD exacerbations were defined as any of the following: an acute COPD exacerbation diagnosis; a claim for an oral antibiotic or an oral corticosteroid on the same day, or within 7 days following an outpatient COPD diagnosis or visit; an inpatient COPD diagnosis; a hospitalization due to a respiratory condition; an emergency department visit with a COPD diagnosis; or a lower respiratory tract infection diagnosis [19]. In the UK, COPD 
exacerbations were defined as an acute COPD exacerbation or respiratory failure diagnosis; a lower respiratory tract infection diagnosis; or a prescription for an oral antibiotic or oral corticosteroid on the same day, or within 7 days following a COPD diagnosis (in line with a previous classification strategy proposed by Rothnie et al.) [20].

\section{Statistical Analysis}

Continuous variables were presented as mean (standard deviation) and/or median (interquartile range $[\mathrm{IQR}])$, and categorical variables were presented as absolute and relative frequencies.

Missing data in covariates or descriptive variables were classified as their own category. In addition, a feasibility assessment was performed before beginning the analyses, and variables with $>75 \%$ missing values were excluded from all analyses.

Sankey plots were generated to visually illustrate the flow of patients from 1MT to 2MT by therapy category.

All analyses were conducted using the Aetion Evidence Platform ${ }^{\circledR}$ (2020; Aetion Inc., New York, NY, USA), a software platform for realworld data analysis, which has been validated for a range of studies [21].

\section{RESULTS}

\section{Patients Initiating 2MT}

Among the 53,473 US patients and 8786 UK patients who initiated 1MT, 7028 (13.1\%) and $2461(28.0 \%)$ patients, respectively, had data indicating switch to $2 \mathrm{MT}$, leaving 46,445 (86.9\%) and 6325 (72.0\%) patients, respectively, without a $2 \mathrm{MT}$ during the study period (Supplementary Table 1 ).

Patient characteristics and treatment choice at 2MT are presented in Tables 2 and 3 for the US and UK, respectively. Patient age, gender distribution, and forced expiratory volume in $1 \mathrm{~s}\left(\mathrm{FEV}_{1}\right) /$ forced vital capacity (FVC) (available in UK data only) were similar at 2MT, irrespective of treatment group, in both the US and the UK.

In the US, the most common maintenance therapies initiated at 2MT were ICS-containing regimens (62.2\% overall; $26.1 \%$ LAMA/LABA/ ICS, and $25.8 \%$ LABA/ICS), followed by LAMA $(20.6 \%)$ and LAMA/LABA (16.0\%).

In the UK, ICS-containing regimens were also the most common maintenance therapy initiated at 2MT (47.5\% overall; $27.8 \%$ LAMA/ LABA/ICS, and $13.7 \%$ LABA/ICS), followed by LAMA/LABA (39.4\%).

\section{Exacerbations}

In the US, $33.6 \%$ of patients initiating 2MT had no record of an exacerbation during the previous year, whereas $23.1 \%$ had 1 and $43.3 \%$ had $\geq 2$. For patients prescribed ICS-containing regimens at $2 \mathrm{MT}$, the proportion with $\geq 2$ exacerbations in the previous year was $48.1 \%$ (LAMA/LABA/ICS), $46.4 \%$ (LAMA/ICS), $40.4 \%$ (ICS only), and $39.3 \%$ (LABA/ICS).

In the UK, $54.9 \%$ of patients initiating $2 \mathrm{MT}$ had no record of an exacerbation during the previous year, whereas $20.9 \%$ had one and $24.2 \%$ had $\geq 2$. For patients prescribed ICScontaining regimens at $2 \mathrm{MT}$, the proportion with $\geq 2$ exacerbations in the previous year was $35.3 \%$ (LAMA/LABA/ICS), 26.6\% (LABA/ICS), $20 \%$ (ICS only), and 22.4\% (LAMA/ICS).

\section{Respiratory Burden and Comorbidities}

In the US, at $2 \mathrm{MT}$, a total of $26.2 \%$ and $19.7 \%$ of patients had recorded upper and lower respiratory tract infections in the previous year, respectively. The percentage of patients with pneumonia at $2 \mathrm{MT}$ was $25.9 \%$ and, for chronic bronchitis, $15.6 \%$. Lung fibrosis was reported in $5.5 \%$ of patients.

In the UK, at $2 \mathrm{MT}$, a total of $44.2 \%$ and $56.8 \%$ of patients had recorded upper and lower respiratory tract infections in the previous year, respectively. The percentage of patients with pneumonia at $2 \mathrm{MT}$ was $9.6 \%$ and, for chronic bronchitis, $0.6 \%$. Lung fibrosis was reported in $1.1 \%$ of patients. 


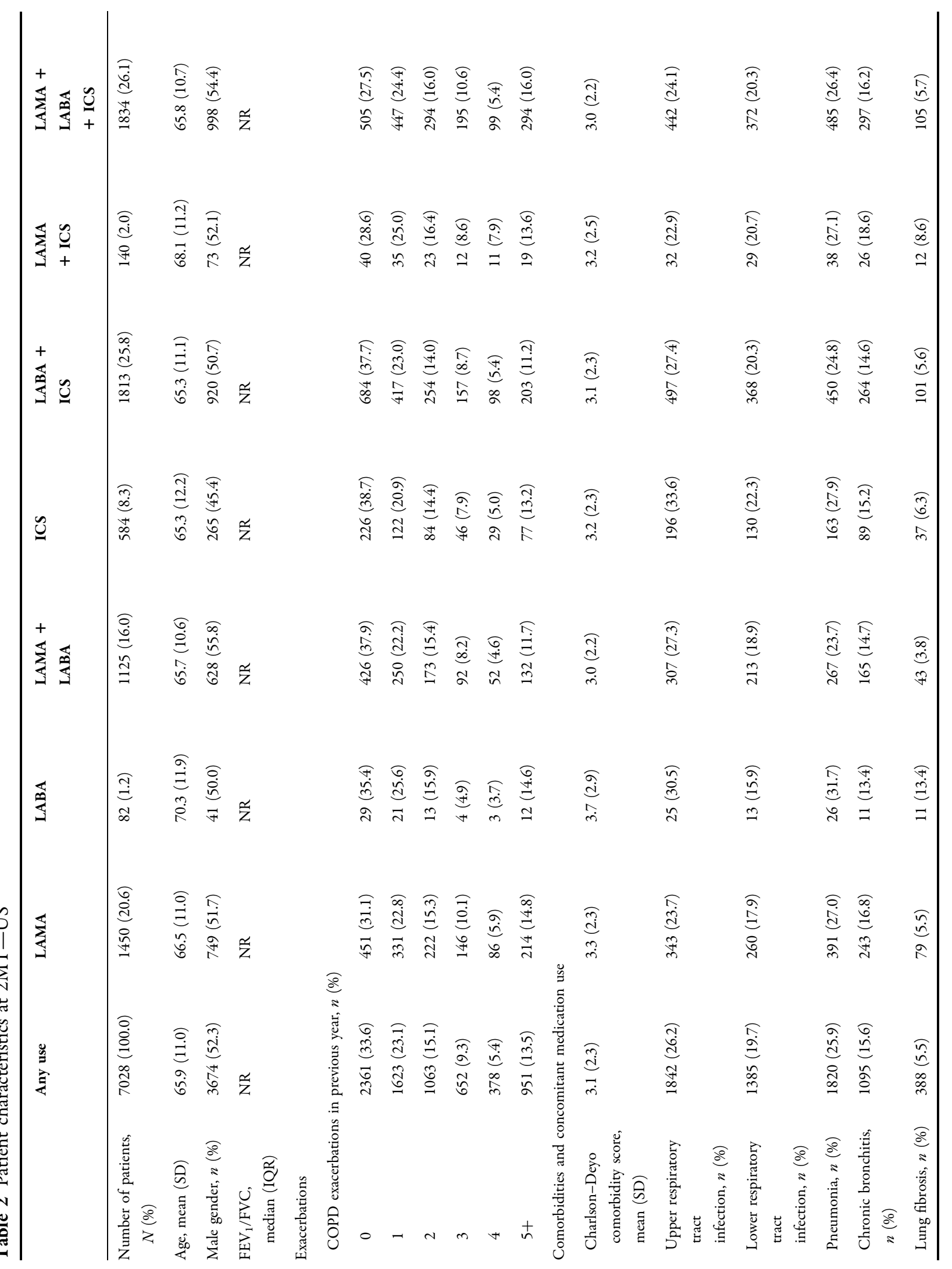




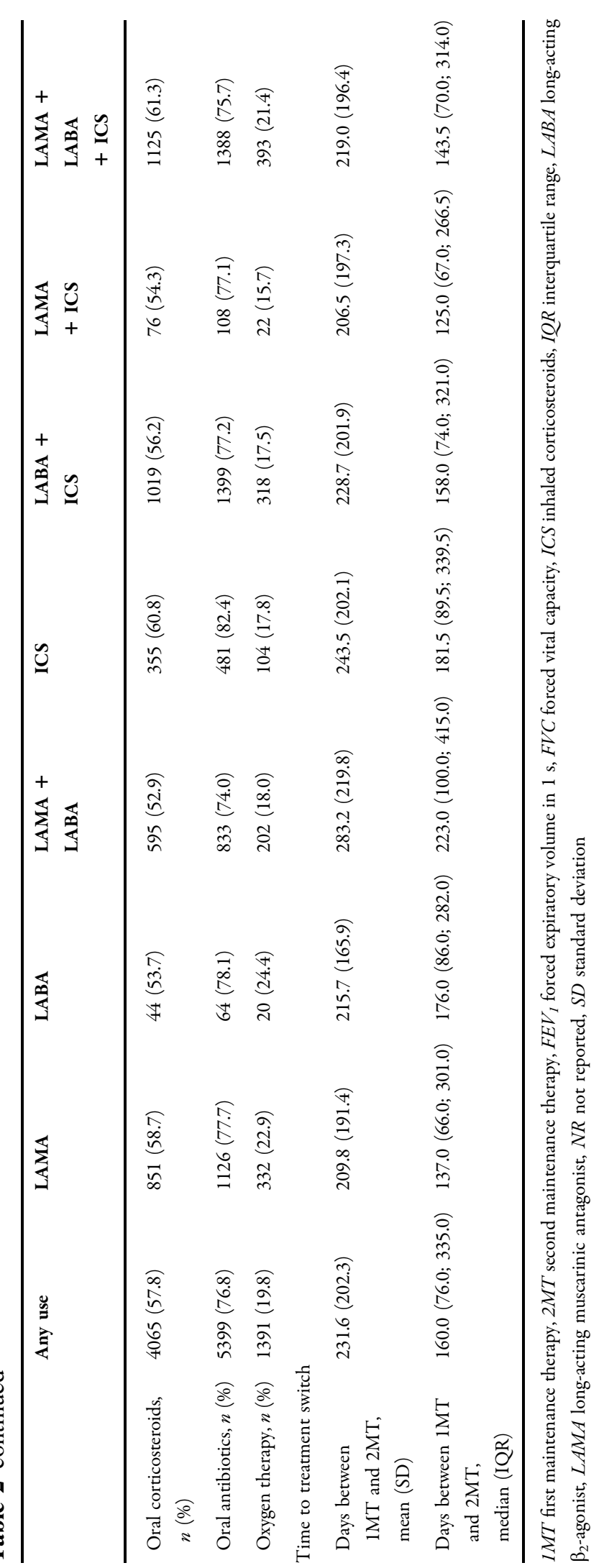




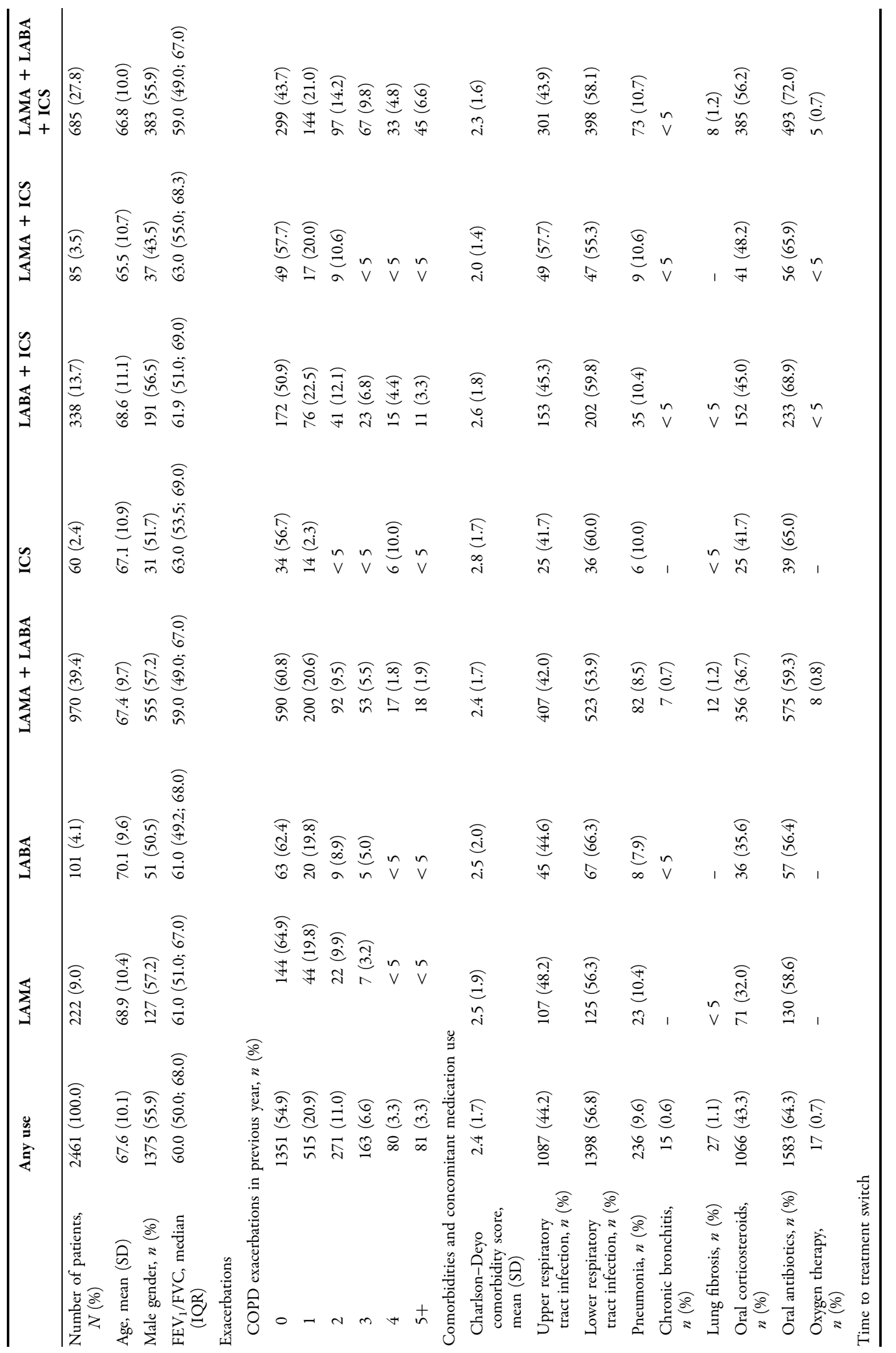


Treatment Transitions Between 1MT and 2MT

Treatment transitions for patients initiating 1MT and 2MT in the US and UK are illustrated via Sankey plots (Fig. 1).

In the US, the most common treatment transition from 1MT to 2MT was LABA/ICS to LAMA/LABA/ICS (13.0\%); in the UK, it was LAMA to LAMA/LABA (32.5\%), followed by LAMA to LAMA/LABA/ICS (14.3\%).

In the US, one in three (36.7\%) patients receiving LABA/ICS at 1MT escalated to LAMA/ LABA/ICS at 2MT, whereas $26.4 \%$ de-escalated to LAMA and $19.9 \%$ switched to LAMA/LABA. Of those receiving LAMA at 1MT, a total of $34.0 \%$ escalated to LAMA/LABA/ICS at 2MT, $32.8 \%$ to LABA/ICS and $23.6 \%$ to LAMA/LABA. Of those receiving LAMA/LABA at 1MT, a total of $44.9 \%$ switched to LABA/ICS and $26.4 \%$ escalated to LAMA/LABA/ICS.

In the $U K$, over half of patients receiving LAMA at 1MT escalated to LAMA/LABA (55.6\%) at $2 \mathrm{MT}$ and $24.5 \%$ escalated to LAMA/LABA/ ICS. Of those receiving LAMA/LABA at 1MT, $50.3 \%$ escalated to LAMA/LABA/ICS and $23.8 \%$ de-escalated to LAMA; of those receiving LABA/ ICS at $1 \mathrm{MT}, 56.8 \%$ escalated to LAMA/LABA/ ICS, whereas $19.2 \%$ switched to LAMA/LABA and $16.6 \%$ de-escalated to LAMA.

\section{Patterns of Treatment Switching}

The demographic and clinical characteristics of patients escalating, de-escalating or switching therapy between 1MT and 2MT are shown in Table 4 (US) and Table 5 (UK). Also shown are the percentages of patients with 0,1 , or $\geq 2$ exacerbations in the previous year. Patterns of treatment switching, expressed as a percentage of all patients with a recorded treatment change from $1 \mathrm{MT}$ to $2 \mathrm{MT}$, are described below.

\section{LABA/ICS to LAMA/LABA/ICS}

Of the patients who had a treatment switch recorded, a total of $13.0 \%$ of patients in the US and $7.8 \%$ in the UK escalated from LABA/ICS at $1 \mathrm{MT}$ to LAMA/LABA/ICS at 2MT. 

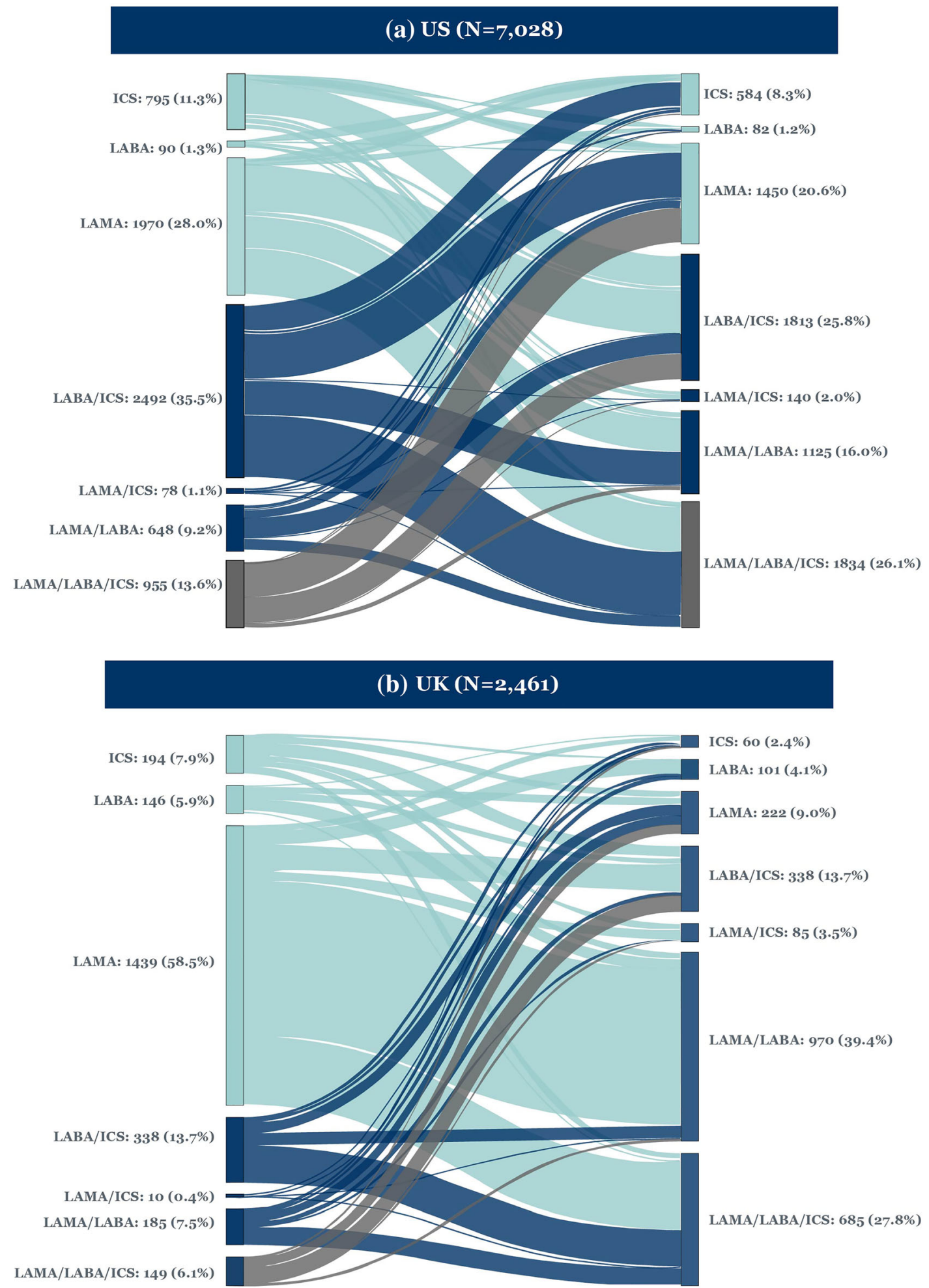

Fig. 1 Sankey plots of treatment transitions from 1MT to 2MT. IMT first maintenance therapy, $2 M T$ second maintenance therapy, ICS inhaled corticosteroids, $L A B A$ long-acting $\beta_{2}$-agonist, $L A M A$ long-acting muscarinic antagonist 


\section{LAMA or LABA to LAMA/LABA}

In total, $6.9 \%$ of patients in the US and $35.1 \%$ in the UK escalated from LAMA or LABA monotherapy at 1MT to LAMA/LABA at 2MT.

\section{LAMA/LABA to LAMA/LABA/ICS}

In total, $2.4 \%$ of patients in the US and $3.8 \%$ in the UK escalated from LAMA/LABA at $1 \mathrm{MT}$ to LAMA/LABA/ICS at 2MT.

\section{$L A B A$ or LAMA to $L A B A / I C S$}

In total, $9.8 \%$ of patients in the US and $6.9 \%$ in the UK escalated from LABA or LAMA monotherapy at $1 \mathrm{MT}$ to LABA/ICS at 2MT.

\section{LABA/ICS to LAMA/LABA}

In total, $7.0 \%$ of patients in the US and $2.6 \%$ in the UK switched from LABA/ICS at 1MT to LAMA/LABA at 2MT.

\section{LAMA/LABA/ICS to LAMA/LABA}

In total, $0.9 \%$ of patients in the US and $0.5 \%$ in the UK de-escalated from LAMA/LABA/ICS at $1 \mathrm{MT}$ to LAMA/LABA at 2MT.

\section{DISCUSSION}

In this retrospective analysis of healthcare data from the US and UK, we found that between one-half and two-thirds of patients were prescribed ICS-containing treatment regimens at 2MT. In the US, the most common treatment transition was LABA/ICS to triple therapy (LAMA/LABA/ICS), whereas in the UK, LAMA monotherapy to LAMA/LABA was the most common transition. In both countries, the proportion of triple therapy use at 2MT was similar, but the prescribing pathways from 1MT to 2MT were different.

In the US, the evaluable patient population at $2 \mathrm{MT}$ was only $13 \%$ of the population studied at 1MT. This is partly explained by the fact that over half of patients were still receiving their $1 \mathrm{MT}$ at the end of the study period. In addition, $37 \%$ of patients did not receive $2 \mathrm{MT}$ because they disenrolled from their health plan. This finding is consistent with the well-documented high turnover rate of patients within US commercial datasets due to patients switching their insurance provider relatively frequently, for example because of changes in employment or marital status. In addition, even with an insurance plan, COPD medications can be prohibitively expensive for some patients; as such, decisions on whether or not to switch medication may be driven by purely cost-related (i.e., non-clinical) factors, influenced by the availability of more affordable generic medications, or promotional coupons or rebate schemes offered by specific manufacturers.

One of the most striking findings in the US dataset was the high proportion of ICS-containing treatment regimens at 2MT. In the accompanying paper in this issue, we reported a high proportion of ICS prescription (66\%) at $1 \mathrm{MT}$, discordant with global and national treatment guidelines, with almost half of patients dispensed LABA/ICS. Similarly, the proportion of ICS use at $2 \mathrm{MT}$ was $62 \%$, with triple therapy and LABA/ICS the most commonly prescribed treatment regimens $(26 \%$ each). The most common transition from 1MT to $2 \mathrm{MT}$ was LABA/ICS to triple therapy, suggesting an escalation in treatment driven by a presumed worsening in symptoms or exacerbations. However, our analysis suggests varying degrees of concordance with guideline recommendations for treatment escalation. Of the patients prescribed a $2 \mathrm{MT}$, around one-third had no record of an exacerbation during the previous year, whereas $23 \%$ and $43 \%$ of patients had 1 and $\geq 2$ recorded exacerbations, respectively. ATS guidelines recommend the use of triple therapy in patients with breathlessness who have had $\geq 1$ exacerbation requiring antibiotics, oral steroids or hospitalization in the previous year. In our analysis, $72 \%$ of patients on triple therapy had $\geq 1$ exacerbation in the year prior to $2 \mathrm{MT}$ (73\% for patients escalating from LABA/ICS and $74 \%$ for those escalating from LAMA/LABA), suggesting that one in four patients were prescribed triple therapy contrary to ATS guidelines.

Regarding de-escalation from triple therapy, we found a very small proportion $(1 \%)$ of patients in the US switching from triple therapy to LAMA/LABA at 2MT (the larger proportion of patients appearing to de-escalate to LAMA or 


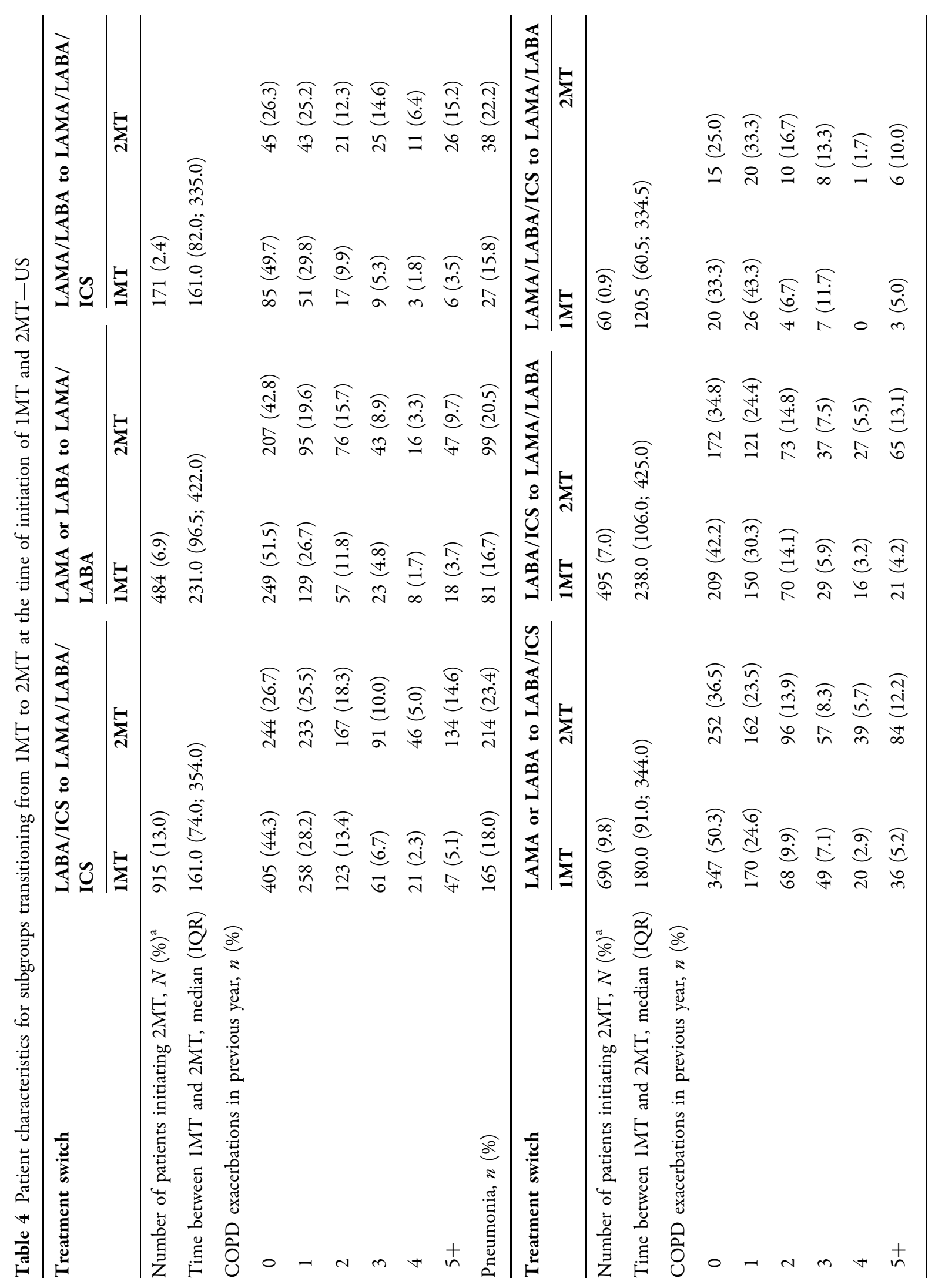




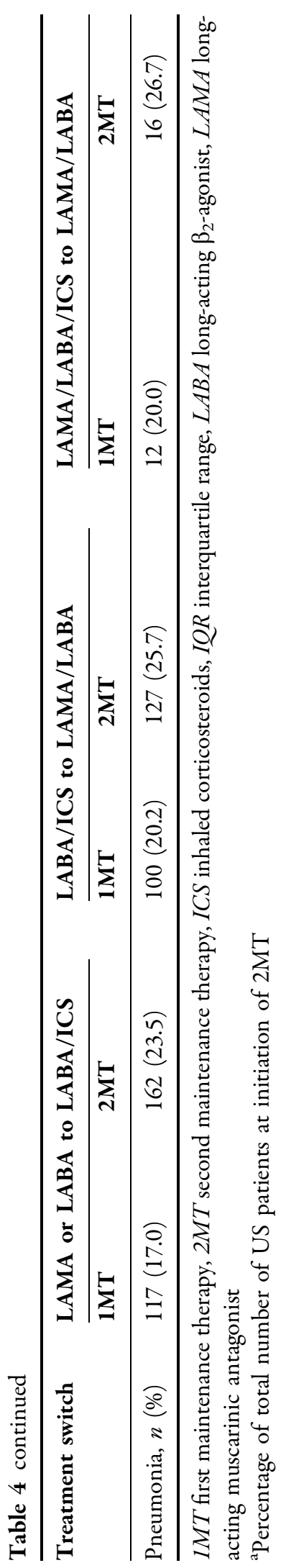

LABA/ICS likely reflects new prescriptions for one component of an open triple combination, and thus cannot be classified as true de-escalation; see Fig. 1). Of note, for patients on LABA/ ICS or triple therapy, GOLD recommends deescalating ICS or switching to LAMA/LABA if there is a lack of response to ICS or pneumonia develops [7]. The ATS guidelines recommend ICS withdrawal for patients receiving triple therapy who have no exacerbations in the previous year [8]. However, in the current analysis, more than one in four US patients $(28 \%)$ on triple therapy at 2MT had no exacerbations in the previous year.

In the UK, the evaluable patient population at 2MT was higher than in the US but still relatively low (28\%), which is largely explained by the fact that more than $80 \%$ of patients were still receiving their $1 \mathrm{MT}$ at the end of the study period. Due to the state-reimbursed nature of the UK healthcare system, treatment switching is not driven by changes in insurance plan or other commercial factors, but largely by patient symptoms and dose-escalation by the treating physician (disenrollment from the CPRD database only occurs if a patient emigrates, for example). Over half of patients (55\%) in the UK had no recorded exacerbations in the year prior to $2 \mathrm{MT}$.

In the UK, the most common treatment regimens at 2MT were LAMA/LABA (40\%) and triple therapy (28\%), and almost half of patients $(48 \%)$ received ICS. The most common transition from $1 \mathrm{MT}$ to $2 \mathrm{MT}$ was single to dual bronchodilation (LAMA to LAMA/LABA) (33\%), followed by direct escalation from LAMA monotherapy to triple therapy (14\%). The 2010-2018 NICE guidelines (applicable to the period of data collection in this analysis) recommend escalation to LAMA/ICS or triple therapy for patients with persistent exacerbations or breathlessness despite treatment with either LAMA or LABA monotherapy, or LABA/ ICS (depending on $\mathrm{FEV}_{1}$ ). However, as the term 'persistent' was not quantified in these guidelines, assessing whether the treatment switches we observed in our study are concordant with the NICE guidelines from this period is challenging. In our study, $28 \%$ of patients were prescribed triple therapy at $2 \mathrm{MT}$, of whom just 


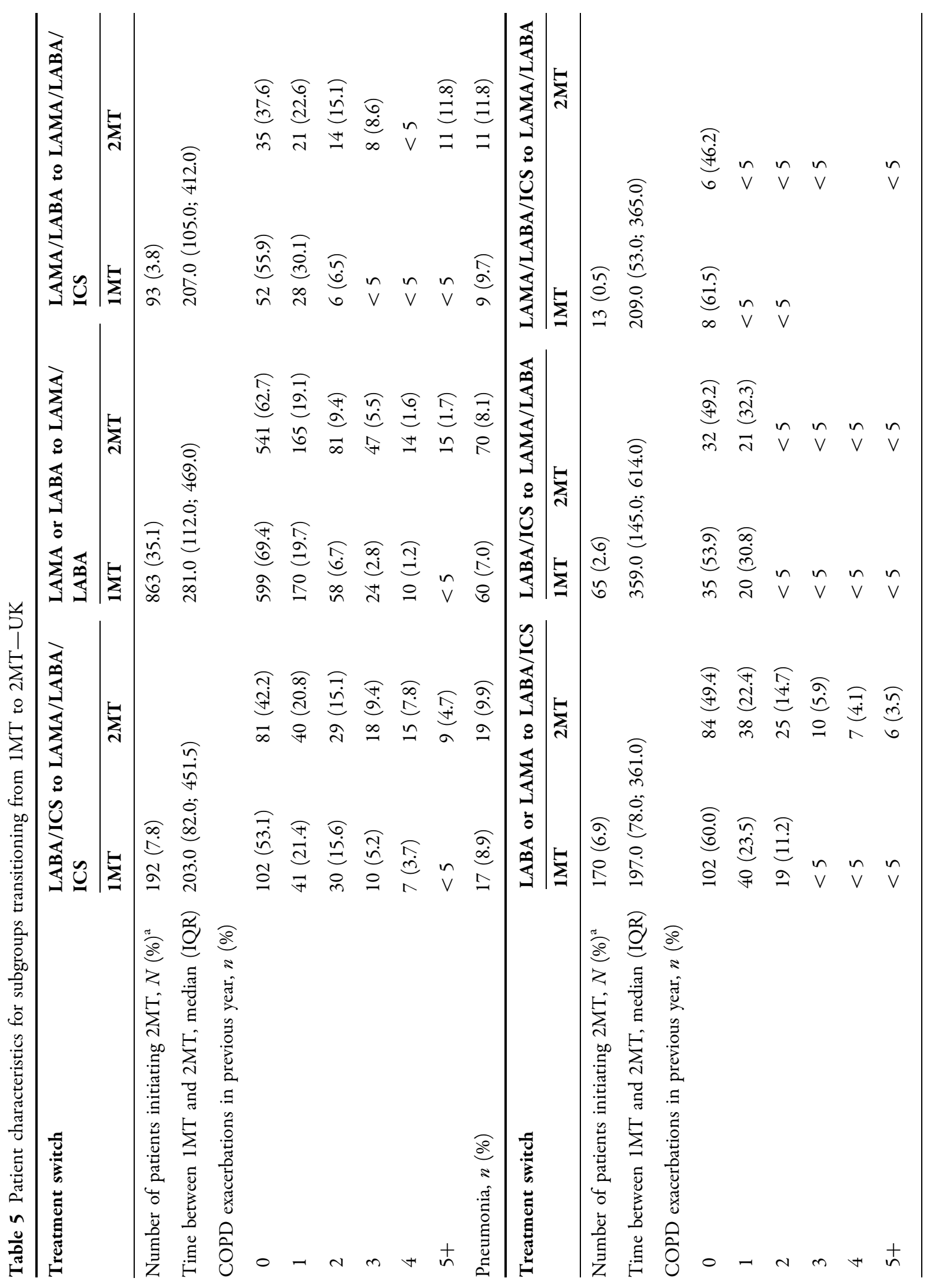




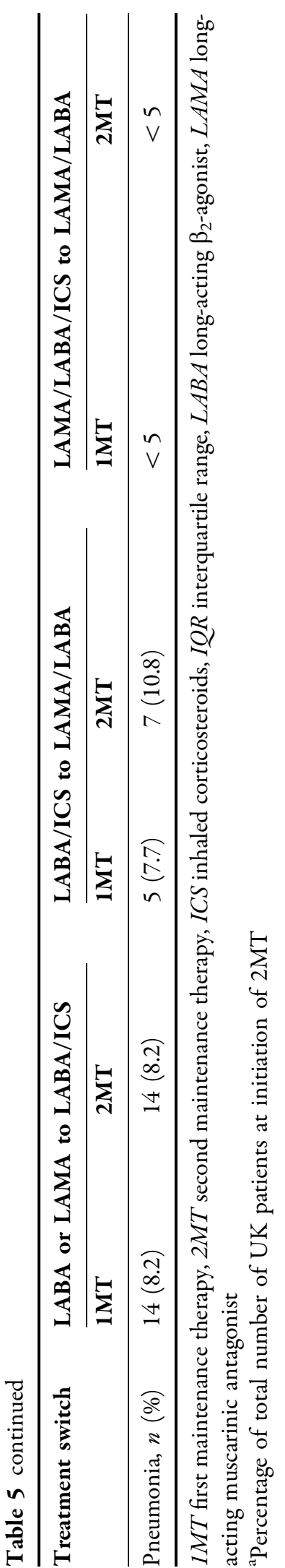

over half reported at least one exacerbation in the previous year. In patients escalating from LABA/ICS or LAMA/LABA to triple therapy, around $60 \%$ experienced at least one exacerbation in the year prior to 2MT. This suggests discordance between UK guidelines and realworld prescribing patterns, with up to two in five patients in this analysis potentially overprescribed ICS based on their exacerbation history. Regarding de-escalation from triple therapy, we found a very small percentage $(0.5 \%)$ of patients in the UK switching from triple therapy to LAMA/LABA at 2MT (as discussed earlier in this section, the larger proportion of patients appearing to de-escalate to LAMA or LABA/ICS likely reflects patients receiving a new prescription for one component of an open triple combination). This is consistent with a previous large-scale analysis of UK primary care health records between 2014 and 2018, in which the annual incidence of ICS withdrawal was also found to be very low (2-3\%) [14].

Our analysis has some similarities with previous studies. In an observational populationbased study of $>34,000$ patients with COPD who initiated triple therapy with LAMA/LABA/ ICS in Spain, most patients initiating triple therapy were non-exacerbators and continued on the same treatment over time, regardless of the severity of disease [22]. This suggests a tendency to over-prescribe ICS and a reluctance for ICS withdrawal, as observed in our study. Conversely, in a recent US study, which compared actual treatment choices according to COPD severity versus the GOLD recommendations, the authors identified gaps between actual use and guideline use and concluded that triple therapy was underutilized [23]. In another UKbased retrospective observational study of patients with COPD, treatment transitions leading to triple therapy in the UK were found to be diverse [24]. The major treatment transition leading to triple therapy was LABA/ICS, reported by $28 \%$ of patients [24]. In our study, $57 \%$ of treatment switches from LABA/ICS at 1MT were escalations to triple therapy, whereas escalation to triple therapy represented only $25 \%$ and $50 \%$ of switches from LAMA and LAMA/LABA, respectively. Another UK study analyzed treatment patterns of LAMA, LABA 
and ICS prescriptions as monotherapy, dual therapy and triple therapy between 2000 and 2016 [25], using the same UK database that we analyzed in this study. Overall, the NICE guidelines were not well adhered to during this period, consistent with our findings. Trends in prescribing patterns for COPD included a rapid increase in triple therapy as first-line therapy, with $41 \%$ of patients maintained on LAMA/ LABA/ICS by 2014 [25]. After this, LAMA/LABA started to gain popularity as 1MT [25]. The current analysis focuses on initiation of $2 \mathrm{MT}$ rather than $1 \mathrm{MT}$, but also noted a predominance of LAMA/LABA at 2MT in the UK (reported in $39 \%$ of patients and representing the most commonly prescribed therapy at 2MT).

Other real-world studies have also noted that over-use of ICS is common [26-28]. However, investigating treatment patterns according to guidelines can be challenging as there could be other factors influencing prescribing patterns that are not covered by the data included in this analysis.

A discussion of the strengths and limitations of the databases and methods of analysis used in this study is provided in the accompanying paper in this issue. In summary, some of the differences between the US and UK may be explained by differences between the data sources (health records from an insurance database in US versus a primary care database in UK), among other factors. This analysis includes patients in the databases with recorded transitions; however, the representativeness of the 2MT population may be compromised due to the high proportion of patients with no $2 \mathrm{MT}$ recorded. A further limitation is the lack of data on additional symptoms (such as cough and sputum production), disease severity (absent from the US dataset), hospitalization or emergency department visits (absent from the UK dataset), and eosinophil levels or severity of exacerbations, which would have provided a more complete picture and helped guide our understanding of treatment transitions between 1MT and 2MT relative to global and national recommendations.

Although exacerbations were recorded in the year prior to initiation of $1 \mathrm{MT}$ or $2 \mathrm{MT}$, the median time between 1MT and 2MT was less than a year (160 days in the US and 218 days in the UK), thus confounding the interpretation of exacerbations in the year prior to 2MT as a driver of treatment decisions. Another potential source of confounding is caused by the difficulty in ascertaining the exact end date of continuous drug use, since we cannot know whether patients had one inhaler left over from a previous prescription. In order to handle this uncertainty, a gap of 14 days was allowed at the end of continuous prescriptions. Lastly, exclusion of patients diagnosed with asthma during the follow-up period is not reflective of realworld practice as a co-diagnosis of asthma would not prevent prescription of a maintenance therapy for COPD.

\section{CONCLUSIONS}

Results suggest that ICS is overused in the US and UK compared with global and national recommendations, with $25-40 \%$ of patients potentially over-prescribed ICS based on their exacerbation history. Conversely, ICS withdrawal is very uncommon. At 2MT, around one in three patients in both the US and UK were prescribed triple therapy (LAMA/LABA/ICS), with patients most commonly escalating from LABA/ICS in the US and LAMA monotherapy in the UK. Use of dual bronchodilation at 2MT was higher in the UK than in the US. Escalation from LAMA to LAMA/LABA appeared to be common in the UK.

\section{ACKNOWLEDGEMENTS}

The authors wish to thank Christina Raabe of Boehringer Ingelheim for her contributions to data analyses and her insightful comments during manuscript review, as well as Edward Yu, Jocelyn Wang, and Gandarvaka Miles of Aetion Inc., contracted by Boehringer Ingelheim, for their contributions to the protocol development and analytic implementation.

Funding. This analysis and the journal's Rapid Service Fee were funded by Boehringer Ingelheim. 
Medical Writing and/or Editorial Assistance. Medical writing assistance, in the form of preparing and revising the manuscript, was funded by Boehringer Ingelheim and provided by Cindy Macpherson via MediTech Media, under the authors' conceptual direction and based on feedback from the authors.

Authorship. All named authors meet the International Committee of Medical Journal Editors (ICMJE) criteria for authorship for this article, take responsibility for the integrity of the work as a whole, and have given their approval for this version to be published.

Author Contributions. JM contributed substantially to the design of the analysis; EMG (as part of Aetion Inc.) provided the data. All authors contributed to the analysis of the data, as well as to the drafting and revision of the manuscript.

Disclosures. Chloe I. Bloom has nothing to disclose. Olaf Jöns is a full-time employee of Boehringer Ingelheim, and Jukka Montonen was a full-time employee of Boehringer Ingelheim at the time of study conduct (current affiliation: Merck KGaA, Darmstadt, Germany). Elizabeth M. Garry is a full-time employee of Aetion, Inc., with stock options. Surya P. Bhatt has received consulting fees from Boehringer Ingelheim and Sanofi, and participated in advisory boards for Sunovion and GlaxoSmithKline. In addition, his academic institute has received research grants from Sanofi and the National Institutes of Health.

Compliance with Ethics Guidelines. As this was an observational study based on de-identified patient-level data from healthcare databases reported in aggregate only, the study did not require ethics committee approval, nor were subjects required to provide informed consent.

Data Availability. The data for this analysis were provided by Aetion Inc. under license and are therefore not publicly available. Upon reasonable request, access to the data can be provided by the corresponding author, with the permission of Aetion Inc.
Open Access. This article is licensed under a Creative Commons Attribution-NonCommercial 4.0 International License, which permits any non-commercial use, sharing, adaptation, distribution and reproduction in any medium or format, as long as you give appropriate credit to the original author(s) and the source, provide a link to the Creative Commons licence, and indicate if changes were made. The images or other third party material in this article are included in the article's Creative Commons licence, unless indicated otherwise in a credit line to the material. If material is not included in the article's Creative Commons licence and your intended use is not permitted by statutory regulation or exceeds the permitted use, you will need to obtain permission directly from the copyright holder. To view a copy of this licence, visit http://creativecommons.org/licenses/by$\mathrm{nc} / 4.0 /$.

\section{REFERENCES}

1. May SM, Li JT. Burden of chronic obstructive pulmonary disease: healthcare costs and beyond. Allergy Asthma Proc. 2015;36(1):4-10.

2. American Lung Association. Learn about COPD. 2020. https://www.lung.org/lung-health-diseases/ lung-disease-lookup/copd/learn-about-copd. Accessed 14 May 2020.

3. Snell N, Strachan D, Hubbard R, Gibson J, GruffyddJones K, Jarrold I. S32 Epidemiology of chronic obstructive pulmonary disease (COPD) in the UK: findings from the British Lung Foundation's 'respiratory health of the nation' project. Thorax. 2016;71(Suppl 3):A20.1-A20.

4. Ford ES, Murphy LB, Khavjou O, Giles WH, Holt JB, Croft JB. Total and state-specific medical and absenteeism costs of COPD among adults aged 18 years in the United States for 2010 and projections through 2020. Chest. 2015;147(1):31-45.

5. The Lancet. UK COPD treatment: failing to progress. Lancet. 2018;391(10130):1550.

6. British Lung Foundation. The battle for breath - the economic burden of lung disease. https://www.blf. org.uk/policy/economic-burden. Accessed 25 Sept 2020. 
7. Global Initiative for Chronic Obstructive Lung Disease. Global strategy for the diagnosis, management, and prevention of chronic obstructive pulmonary disease (2021 report). 2020. https:// goldcopd.org/wp-content/uploads/2020/11/GOLDREPORT-2021-v1.1-25Nov20_WMV.pdf. Accessed 2 Feb 2021.

8. Nici L, Mammen MJ, Charbek E, et al. Pharmacologic management of chronic obstructive pulmonary disease. An official American Thoracic Society clinical practice guideline. Am J Respir Crit Care Med. 2020;201(9):e56-69.

9. Chalmers JD, Laska IF, Franssen FME, et al. Withdrawal of inhaled corticosteroids in COPD: a European Respiratory Society guideline. Eur Respir J. 2020;55(6):2000351.

10. National Institute for Health and Care Excellence. Chronic obstructive pulmonary disease in over 16s: diagnosis and management. 2018. https://www. nice.org.uk/guidance/ng115/resources/chronicobstructive-pulmonary-disease-in-over-16sdiagnosis-and-management-pdf-66141600098245. Accessed 29 Apr 2021.

11. Barrecheguren M, Monteagudo M, Ferrer J, et al. Treatment patterns in COPD patients newly diagnosed in primary care. A population-based study. Respir Med. 2016;111:47-53.

12. Diette GB, Dalal AA, D'Souza AO, Lunacsek OE, Nagar SP. Treatment patterns of chronic obstructive pulmonary disease in employed adults in the United States. Int J Chronic Obstr Pulm Dis. 2015;10: 415-22.

13. Chalmers JD, Tebboth A, Gayle A, Ternouth A, Ramscar N. Determinants of initial inhaled corticosteroid use in patients with GOLD A/B COPD: a retrospective study of UK general practice. NPJ Prim Care Respir Med. 2017;27(1):1-8.

14. Bloom CI, Douglas I, Usmani OS, Quint JK. Inhaled corticosteroid treatment regimens and health outcomes in a UK COPD population study. Int J Chronic Obstr Pulm Dis. 2020;15:701-10.

15. Suissa S, Kezouh A, Ernst P. Inhaled corticosteroids and the risks of diabetes onset and progression. Am J Med. 2010;123(11):1001-6.

16. Suissa S, Dell'Aniello S, Ernst P. Comparative effectiveness and safety of LABA-LAMA vs LABA-ICS treatment of COPD in real-world clinical practice. Chest. 2019;155(6):1158-65.

17. Price D, Yawn B, Brusselle G, Rossi A. Risk-to-benefit ratio of inhaled corticosteroids in patients with COPD. Prim Care Respir J. 2013;22(1):92-100.
18. Dahl R. Systemic side effects of inhaled corticosteroids in patients with asthma. Respir Med. 2006;100(8):1307-17.

19. Rothnie KJ, Müllerová $\mathrm{H}$, Thomas $\mathrm{SL}$, et al. Recording of hospitalizations for acute exacerbations of COPD in UK electronic health care records. Clin Epidemiol. 2016;8:771-82.

20. Rothnie KJ, Mullerova H, Hurst JR, et al. Validation of the recording of acute exacerbations of COPD in UK primary care electronic healthcare records. PLoS One. 2016;11(3):e0151357.

21. Wang S, Verpillat P, Rassen J, Patrick A, Garry E, Bartels D. Transparency and reproducibility of observational cohort studies using large healthcare databases. Clin Pharmacol Ther. 2016;99(3): 325-32.

22. Monteagudo M, Nuñez A, Solntseva I, et al. Treatment pathways before and after triple therapy in COPD: a population-based study in primary care in Spain. Arch Bronconeumol. 2021;57:205-13.

23. Schabert V, Shah S, Holmgren U, Cabrera C. Prescribing pathways to triple therapy in patients with chronic obstructive pulmonary disease in the United States. Ther Adv Respir Dis. 2021;15: 17534666211001018.

24. Quint JK, Venerus A, O'Leary C, et al. Prescribing pathways to triple therapy: a retrospective observational study of adults with chronic obstructive pulmonary disease in the UK. Int J Chronic Obstr Pulm Dis. 2020;15:3261.

25. Bloom CI, Elkin SL, Quint JK. Changes in COPD inhaler prescriptions in the United Kingdom, 2000 to 2016. Int J Chronic Obstr Pulm Dis. 2019;14: 279-87.

26. Halpin DMG, de Jong HJI, Carter V, Skinner D, Price D. Distribution, temporal stability and appropriateness of therapy of patients with COPD in the UK in relation to GOLD 2019. EClinicalMedicine. 2019;14:32-41.

27. Hurst JR, Dilleen M, Morris K, Hills S, Emir B, Jones R. Factors influencing treatment escalation from long-acting muscarinic antagonist monotherapy to triple therapy in patients with COPD: a retrospective THIN-database analysis. Int J Chronic Obstr Pulm Dis. 2018;13:781-92.

28. Moretz C, Sharpsten L, Bengtson LG, et al. Realworld effectiveness of umeclidinium/vilanterol versus fluticasone propionate/salmeterol as initial maintenance therapy for chronic obstructive pulmonary disease (COPD): a retrospective cohort study. Int J Chronic Obstr Pulm Dis. 2019;14: 1721-37. 